\title{
Ocean currents drive secondary contact between Anguilla marmorata populations in the Indian Ocean
}

\author{
P. A. Gagnaire ${ }^{1, *}$, Y. Minegishi ${ }^{1,2}$, J. Aoyama ${ }^{2}$, E. Réveillac ${ }^{3}$, T. Robinet $^{4}$, P. Bosc ${ }^{5}$, \\ K. Tsukamoto ${ }^{2}$, E. Feunteun ${ }^{4}$, P. Berrebi ${ }^{1}$ \\ ${ }^{1}$ Institut des Sciences de l'Evolution, Université de Montpellier II, CC 065, Place E. Bataillon, 34095 Montpellier cedex 5, France \\ ${ }^{2}$ Ocean Research Institute, University of Tokyo, 1-15-1 Minamidai, Nakano-ku, 164-8639 Tokyo, Japan \\ ${ }^{3}$ Littoral Environnement et Sociétés, Institut du Littoral et de l'Environnement, 2 rue Olympe de Gouges, 17000 La Rochelle, \\ France \\ ${ }^{4}$ Biologie des Organismes Marins et Ecosystèmes, Muséum National d'Histoire Naturelle, Laboratoire Maritime et \\ Musée de la Mer de Dinard, 17 Av. Georges V, 35801 Dinard, France \\ ${ }^{5}$ Association Réunionnaise de Développement de l'Aquaculture, Centre des Eaux Douces, Les Sables, 97427 Etang-Salé, \\ Ile de La Réunion, France
}

\begin{abstract}
Understanding the evolutionary processes underlying population structuring of freshwater eels is an essential step toward comprehending their exceptional life cycle. However, in order to infer evolutionary scenarios that account for the genetic structure of current populations, it is necessary to unravel the history of gene flow from the onset of population divergence to the present. We used a combination of population-genetics methods and Bayesian coalescent analyses, to search specifically for the gene flow history that could explain contemporary genetic patterns of 2 Anguilla marmorata populations previously identified in the Indian Ocean. The population structure of A. marmorata was analyzed by genotyping 444 eels sampled from both sides of the Indian Ocean. Using 2 mitochondrial 16S rRNA single-nucleotide polymorphisms (SNPs) and 10 nuclear microsatellite loci, we first provided corroborative evidence of the existence of 2 genetic stocks: the Sumatran and the southwestern Indian Ocean (SWIO) populations (nuclear $F_{\mathrm{ST}}=0.025$ to 0.039 ). High frequencies of Sumatran haplotypes were found in SWIO localities (27 to $43 \%$ ). Fitting the isolation-with-migration model to 16S rRNA sequence data led us to reject the hypotheses of inherited ancestral polymorphism and divergence with gene flow, but supported a recent secondary contact with unidirectional migration following a period of isolation. This scenario was confirmed by a cytonuclear disequilibrium found in SWIO, which also indicated that unidirectional migration was in progress. Finally, fitting simulated models of population composition to Bayesian assignments estimated from nuclear data suggested that Sumatran migrants are integrated in the SWIO breeding pool after their dispersal induced by the South Equatorial Current.
\end{abstract}

KEY WORDS: Anguilla marmorata · Population evolutionary history · Allopatric divergence · Secondary contact $\cdot$ Cytonuclear disequilibrium $\cdot$ Unidirectional gene flow

Resale or republication not permitted without written consent of the publisher

\section{INTRODUCTION}

In marine species, the lack of physical barriers to dispersal and migration hinders population differentiation (Waples 1998). On the other hand, freshwater fishes whose ecological habitat is spatially fragmented and delimited downstream by the sea, cumulate res- tricted dispersal and migration capacities that favor population structuring (Ward et al. 1994). Weak genetic differentiation in Anguilla species could result from 2 main features, as proposed for the 3 northern temperate regions eel species, $A$. anguilla, A. rostrata and A. japonica (Sang et al. 1994, Wirth \& Bernatchez 2001, 2003). First, reproduction occurs in a species- 
specific spawning area where the putative absence of assortative mating should not allow genetic differentiation (Wirth \& Bernatchez 2001). Second, larval homing to parental habitat is unlikely because a more or less passive transport of leptocephali across the ocean by currents is thought to randomly distribute the larval pool to the continental water systems (Sang et al. 1994, McCleave et al. 1998). Therefore, temperate-region eel species have long been considered as a paradigm of panmixia at the species scale. This theory, which emerged with the discovery of the A. anguilla spawning ground in the Sargasso Sea in 1920 (Schmidt 1925), gave rise to many studies aimed at seeking genetic structure in a seemingly panmictic species. At first, neither nuclear allozymic markers nor mitochondrial DNA sequences had allowed the identification of distinct genetic pools in samples from different locations of the European eel's distribution area (De Ligny et al. 1973, Comparini et al. 1977, Lintas et al. 1998). More recently, 2 studies using microsatellite nuclear markers reported genetic variation between eel samples of different continental locations (Daemen et al. 2001, Wirth \& Bernatchez 2001), and a positive correlation between genetic and geographic distances was independently shown with microsatellite and allozymic markers (Wirth \& Bernatchez 2001, Maes \& Volckaert 2002). The panmixia theory in the European eel was thus weakened by these results, until recent surveys showed that the structure previously evidenced could be explained by temporal genetic variation (Dannewitz et al. 2005, Pujolar et al. 2006). Overall, these findings suggest a population structure comparable to that of many marine fishes, showing a more or less panmictic population scheme with a low degree of genetic differentiation. In this context, where most mechanisms tend towards genetic homogenization, understanding how speciation can happen in eels is a challenging issue.

Some answers could be provided by the study of tropical eel species. The giant mottled eel Anguilla marmorata, which is the most largely distributed eel species, is unlikely to present such a simple population structure. This tropical species can be found within a large Indo-Pacific zone ranging from the eastern side of Africa to the Tuamotu Archipelago in Polynesia passing by Indonesia, and from South Africa to southern Japan. As these distant continental habitats are connected to different oceanic current systems that show private trajectories, a single spawning place from which larval dispersal would cover the whole distribution area is hardly conceivable. However, there is still little information available concerning the number and the location of spawning sites for A. marmorata. On the basis of leptocephali collections, Jespersen (1942) suggested the existence of several spawning areas across the species range. For instance, he captured a few large leptocephali larvae of $A$. marmorata northeast of Madagascar and hundreds of young leptocephali southwest of Sumatra, suggesting 2 possible breeding places in the Indian Ocean. However, a Sumatran spawning site could not be confirmed since species identification of small larvae was not possible. On the other hand, ages at metamorphosis obtained from otolith analyses of eels collected in the southwestern Indian Ocean (SWIO) showed such a large variation (60 to $180 \mathrm{~d}$ ), that no spawning area location could be rejected on the basis of larval dispersal duration (Robinet et al. 2003, 2008, Réveillac et al. 2008). So far, the only $A$. marmorata spawning ground discovered as a result of leptocephali captures overlaps that of A. japonica in the western North Pacific (Miller et al. 2002). Recent molecular investigations based on mitochondrial control region variation revealed the existence of several geographic populations of A. marmorata, located around the North Pacific, Guam, Madagascar, Sumatra and the South Pacific (Ishikawa et al. 2004, Minegishi et al. 2008). In the Indian Ocean, however, the genetic structure is still imprecisely described. First, the small nuclear differentiation suggested by amplified fragment length polymorphism (AFLP) marker variation between SWIO and Sumatra (Ishikawa et al. 2004) was not confirmed by microsatellite markers (Minegishi et al. 2008). Second, discordant branches appeared in the phylogeographic control region trees, as some individuals from Madagascar and Reunion Island clustered with the Sumatran samples, whereas most SWIO individuals were robustly grouped into a divergent cluster containing only SWIO haplotypes (Ishikawa et al. 2004, Minegishi et al. 2008). Overall, the genetic studies of $A$. marmorata suggested the existence of population-specific spawning areas in different oceanic divisions. Therefore, each eel population could be characterized by its own migration loop (i.e. conceptual migration route connecting the population's spawning area and its growth habitat, Tsukamoto et al. 2002) in a particular ocean current system (Ishikawa et al. 2004).

In these efforts to understand the significant evolutionary processes prevailing in eels, most attention has been devoted to the mechanisms initiating the appearance and isolation of these migration loops, resulting in gene flow breaking and population divergence (Tsukamoto et al. 2002). Allopatric differentiation, which could be the underlying mechanism of population divergence, has never been clearly demonstrated in freshwater eels, however. Conversely, the possible roles of processes such as ongoing migration during divergence or secondary contacts after isolation, have not been fully considered in spite of their evolutionary relevance. In the Indian Ocean, Anguilla marmorata 
provides an interesting model to study these questions, as the patterns of genetic variation previously observed could alternatively derive from inherited ancestral polymorphism, differentiation with gene flow or secondary contact after divergence. New analytic tools separating the effects of time and gene flow on the levels of genetic divergence were recently suggested as a powerful means to disentangle these alternatives (reviewed in Nosil 2008).

In the present study, we first re-examined Anguilla marmorata's current population genetic structure in the Indian Ocean using 2 mitochondrial singlenucleotide polymorphisms (SNPs) and 10 microsatellite markers on specimens collected in SWIO and Sumatra. Second, we tested the hypothesis of allopatric divergence foregoing a secondary contact between the SWIO and Sumatra populations by fitting the isolation-with-migration model on mitochondrial data. We then sought an association between mitochondrial haplotypes and nuclear genotypes to validate the secondary contact hypothesis and test for interbreeding. Finally, we constructed population models with simulated genetic data to estimate the population composition that most likely explains the cytonuclear genetic patterns observed in each locality. Our results confirm a mitochondrial and nuclear differentiation between western and eastern Indian Ocean populations, and support an evolutionary scenario of allopatric divergence followed by a recent asymmetrical secondary contact due to larval dispersal by the South Equatorial Current.

\section{MATERIALS AND METHODS}

Samples. A total of 444 eels were caught by electrofishing. Young specimens measuring less than $200 \mathrm{~mm}$ total length, for which morphological species identification was uncertain or impossible, were all identified by semi-multiplex PCR (Gagnaire et al. 2007) to validate their classification as Anguilla marmorata. The overall sample consisted of 312 glass eels and elvers of total length ranging from 46 to $149 \mathrm{~mm}$ and 132 yellow eels ranging from 150 to $869 \mathrm{~mm}$. Glass eels and elvers measuring less than $150 \mathrm{~mm}$ were considered to have recruited within the sampling year (Robinet et al. 2003) and were used as temporal samples. 398 specimens were sampled in the western
Indian Ocean (102 in Mayotte Island, 88 in Madagascar, 106 in Mauritius Island and 102 off Reunion Island) and 46 in rivers on the western coast of Sumatra (Fig. 1). The year and location of sampling, number of individuals and their life stage are listed in Table 1.

DNA extraction. All samples were preserved in 95\% ethanol. Genomic DNA was isolated from fin clips for yellow eels or muscle tissue for glass eels and elvers following the classical phenol-chloroform extraction protocol (Sambrook et al. 1989) or using a $5 \%$ w/v Chelex extraction solution (BioRad) after proteinase K digestion.

Mitochondrial SNP genotyping. Two mitochondrial SNPs located at nucleotide positions 432 and 562 of the 16S rRNA gene were genotyped in each specimen. Previous alignment of sequences obtained from specimens sampled throughout the whole geographical distribution of Anguilla marmorata revealed that position 432 was occupied by either a $G$ or an $A$, and position 562 by a $\mathrm{C}$ or a $\mathrm{T}$ (Y. Minegishi unpubl. data). Since the North Pacific population, which is the most basal lineage in A. marmorata (Minegishi et al. 2008), was fixed for the G432-C562 association, we considered it as the ancestral combination. Here, the genotyping procedure was based on the use of 2 forward and 2 reverse primers (Table 2) to perform 4 independent amplification tests for each individual. The external primers

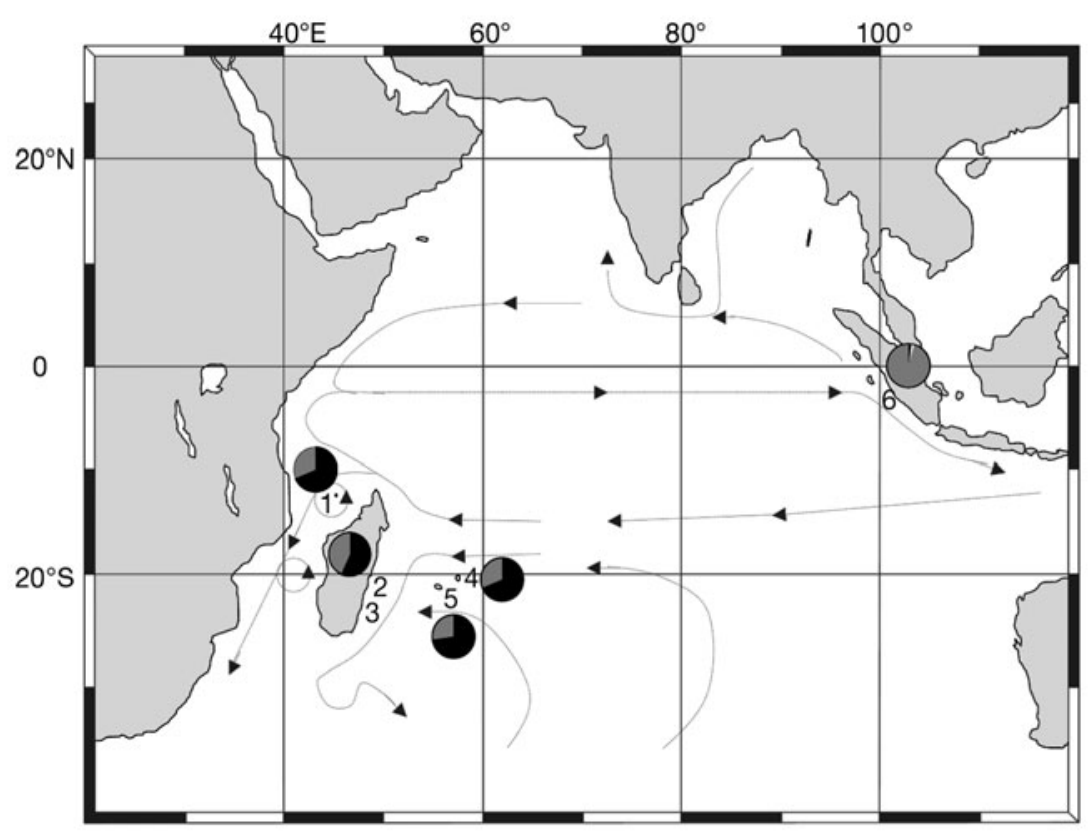

Fig. 1. Anguilla marmorata. Indian Ocean map showing sampling sites and the composition of 16S rRNA single-nucleotide polymorphisms (SNPs) found in each locality. 1: Mayotte; 2: Mananjary (Madagascar); 3: Farafangana (Madagascar); 4: Mauritius; 5: Reunion; 6: Sumatra. The 3 SNP haplotypes found in this study are: $(\bullet)$ for the AT type; $(\bigcirc)$ for the GC type; and (O) for the only AC combination (identified in Sumatra). Prominent branches of surface ocean currents are represented as arrows corresponding to the January-February configuration (Schott \& McCreary 2001) 
Table 1. Anguilla marmorata. Details of samples collected in the different Indian Ocean localities

\begin{tabular}{|c|c|c|c|c|c|}
\hline $\begin{array}{l}\text { Sampling } \\
\text { locality }\end{array}$ & $\begin{array}{c}\text { Sample } \\
\text { abbreviation }\end{array}$ & $\begin{array}{l}\text { Sampling } \\
\text { period }\end{array}$ & $\begin{array}{l}\text { Sampling } \\
\text { size }\end{array}$ & $\begin{array}{l}\text { Total length } \\
\text { (mm) }\end{array}$ & Development stage \\
\hline \multirow[t]{3}{*}{ Mayotte } & May $^{\text {b }}$ & $2005-2006$ & 102 & $47-487$ & From glass eel to yellow eel \\
\hline & MayA5 ${ }^{a}$ & April 2005 & 57 & $47-149$ & From glass eel to elver \\
\hline & MayM6 $^{\mathrm{a}}$ & May 2006 & 15 & $49-136$ & From glass eel to elver \\
\hline Madagascar & Mad $^{\mathrm{b}}$ & $2005-2006$ & 88 & $46-53$ & Glass eel \\
\hline Mananjary ${ }^{\mathrm{c}}$ & ManF6 $^{\mathrm{a}}$ & February 2006 & 50 & $47-53$ & Glass eel \\
\hline Farafangana ${ }^{\mathrm{C}}$ & FarJ6 $^{\mathrm{a}}$ & January 2006 & 33 & $46-52$ & Glass eel \\
\hline \multirow[t]{2}{*}{ Mauritius } & $\mathrm{Mau}^{\mathrm{b}}$ & April 2005 & 106 & $45-752$ & From glass eel to yellow eel \\
\hline & MauA $5^{\mathrm{a}}$ & April 2005 & 81 & $45-146$ & From glass eel to elver \\
\hline \multirow[t]{3}{*}{ Reunion } & $\mathrm{Reu}^{\mathrm{b}}$ & 2001-2006 & 102 & $50-291$ & From glass eel to yellow eel \\
\hline & ReuAM5 $5^{a}$ & April-May 2005 & 21 & $50-118$ & From glass eel to elver \\
\hline & ReuAMS6 ${ }^{\mathrm{a}}$ & April-May \& September 2006 & 50 & $50-147$ & From glass eel to elver \\
\hline Sumatra & Sum $^{\mathrm{b}}$ & $1997-2003$ & 46 & $155-869$ & From elver to yellow eel \\
\hline
\end{tabular}

Table 2. Anguilla marmorata. Details of the primers used in this study. Microsatellite primer sets were initially designed for A. japonica (AJMS and AjTR) and A. rostrata (Aro) (see references in 'Materials and methods'), PCR conditions such as annealing temperature were adapted here to obtain suitable amplifications in A. marmorata

\begin{tabular}{|c|c|c|c|c|c|}
\hline $\begin{array}{l}\text { Locus } \\
\text { name }\end{array}$ & Primer name & Primer sequence $\left(5^{\prime}-3^{\prime}\right)$ & $\begin{array}{l}\text { Primer } \\
\text { length }\end{array}$ & $\begin{array}{l}\text { Primer } \\
\text { labelling }\end{array}$ & $\begin{array}{c}\text { Annealing } \\
\text { temperature }\left({ }^{\circ} \mathrm{C}\right)\end{array}$ \\
\hline \multirow[t]{2}{*}{ AJMS-3 } & FAJMS-3 & GGTATGAATGCAGGCGTTTATG & 22 & 5'-Cy5 & 58 \\
\hline & RAJMS-3 & GCAACCGATTTGATCTCCAG & 20 & & \\
\hline \multirow[t]{2}{*}{ AJMS-6 } & FAJMS-6 & ACAGAGCCAGACAAACAGAC & 20 & 5'-Cy3 & 58 \\
\hline & RAJMS-6 & GGTCAGCAAGCAAAACGAAC & 20 & & \\
\hline \multirow[t]{2}{*}{ AJMS-10 } & FAJMS-10 & TGTCTAACACTAAGAAAAGGAGAGG & 25 & 5'-Fluorescein & 58 \\
\hline & RAJMS-10 & GGCTGCCAGTATCTTCTCAAAG & 22 & & \\
\hline \multirow[t]{2}{*}{ AjTR-04 } & FAjTR-04 & CACCCTTGCCCTATTTTGATA & 21 & 5'-Cy3 & 57 \\
\hline & RAjTR-04 & GCTGAGTCATGATCACCTGT & 20 & & \\
\hline \multirow[t]{2}{*}{ AjTR-12 } & FAjTR-12 & AACGTTAGTCCCTAGGTTCC & 20 & 5'-Fluorescein & 55 \\
\hline & RAjTR-12 & TAAGGGTGTTATATGTTCAG & 20 & & \\
\hline \multirow[t]{2}{*}{ AjTR-37 } & FAjTR-37 & AGACCTTATGTCACCTTATGCT & 22 & 5'-Cy3 & 55 \\
\hline & RAjTR-37 & AAGATGTTAAATTCAATTGTGC & 22 & & \\
\hline \multirow[t]{2}{*}{ AjTR-45 } & FAjTR-45 & GCGCATGGAGAACTCTAAT & 19 & 5'-Cy5 & 55 \\
\hline & RAjTR-45 & CAATAGAGTGAGGACAGTAGA & 21 & & \\
\hline \multirow{2}{*}{ Aro054 } & FAro054 & СТCAACTCCAGCACACTGGA & 20 & 5'-Fluorescein & 58 \\
\hline & RAro054 & ACAAAATAGCTCCGTAACAC & 20 & & \\
\hline \multirow{2}{*}{ Aro063 } & FAro063 & CCAGATACCTTGACAACGGC & 20 & 5'-Cy5 & 58 \\
\hline & RAro063 & TCAAGAGCTTCCTGACCСТC & 20 & & \\
\hline \multirow{2}{*}{ Aro095 } & FAro095 & GGCTGTTATTCTGGACGTCG & 20 & $5^{\prime}-\mathrm{Cy} 5$ & 57 \\
\hline & RAro095 & CCСТAAGTATCCTACATACAG & 21 & & \\
\hline F314 & F314 & GTCTCTGTGGCAAAAGAGT & 19 & & 59 \\
\hline $\mathrm{F} 408$ & $\mathrm{~F} 408$ & TCAGCCTTATGTAATTCTATAACCA & 25 & & 59 \\
\hline R578 & R578 & TGCTTTTGGGCCCACTA & 17 & & 59 \\
\hline R618 & R618 & CTGCATTTACCGGAGCTTTA & 20 & & 59 \\
\hline
\end{tabular}

F314 and R618 that were nested in conserved regions at the species level were used as a positive control, leading to a $305 \mathrm{bp}$ amplification product. The internal primers F408 and R578 had their 3' end at positions 432 and 562, and were designed to hybridize the haplotypes A432 and T562, respectively. Thus, the use of this pair of primers led to a $171 \mathrm{bp}$ amplicon in individuals presenting both A432 and T562. The use of the primer pair F314/R578 led to a $275 \mathrm{bp}$ amplicon in all
T562 individuals, and of F408/R618 to a 211 bp molecule in all A432 samples. G432-C562 specimens were only positive for the control amplification. PCRs were initiated by a $3 \mathrm{~min}$ denaturation step followed by 35 cycles of $30 \mathrm{~s}$ denaturation at $95^{\circ} \mathrm{C}, 30 \mathrm{~s}$ annealing at $59^{\circ} \mathrm{C}$, and $30 \mathrm{~s}$ extension at $72^{\circ} \mathrm{C}$. Reactions were ended by a 2 min final extension step at $72^{\circ} \mathrm{C}$. The amplification product lengths were determined by comparison with a 100 bp-scale size marker after 
electrophoresis on a $1.5 \%$ agarose gel stained with ethidium bromide.

Microsatellite genotyping. Genetic variation was assessed at 10 nuclear microsatellite loci developed for Anguilla japonica and A. rostrata. These were AJMS-3, AJMS-6 and AJMS-10 (Tseng et al. 2001), AjTR-4, AjTR-12, AjTR-37 and AjTR-45 (Ishikawa et al. 2001), and Aro054, Aro063 and Aro095 (Wirth \& Bernatchez 2001). For each locus, the forward primer was 5'-labeled with one of the following fluorochromes: fluorescein, CY3 or CY5 (Table 2). PCR conditions were identical to those for SNP genotyping, except for the annealing temperature, which was adapted for each locus (Table 2). Genotypes were obtained after electrophoresis with a DNA ladder on an $8 \%$ acrylamide denaturing gel scanned with the FMBIO II Multi-View (Hitachi) and analyzed with the software FMBIO Analysis 8.0.

Population genetic and statistical analyses. We calculated allelic diversity and heterozygosity (observed and non-biased expected heterozygosity $\left[H_{\mathrm{o}}\right.$ and $H_{\mathrm{e}}$ respectively] under Hardy-Weinberg equilibrium [HWE]), and tested deviation from HWE, linkage disequilibrium between pairs of loci and genetic differentiation with GENEPOP 3.4 (Raymond \& Rousset 1995). Allelic frequency variations between samples were evaluated by testing the null hypothesis of homogeneity in allelic distribution using Fisher's exact test assessed by Markov chain method (10 4 iterations). Population structure was inferred with Wright's fixation index $\left(F_{\mathrm{ST}}\right)$ estimated by $\theta$ (Weir \& Cockerham 1984) as implemented in GENETIX 4.05 (Belkhir et al. 2004 ). The significance of multilocus $F_{\mathrm{ST}}$ was evaluated by permutation tests $\left(10^{4}\right.$ replicates $)$. Bonferroniadjusted $\mathrm{p}$ values were provided each time independent tests were performed on the same data set.

To evaluate the relative proportions of total genetic variation explained by differentiation between Sumatra and SWIO regions versus among SWIO localities, we partitioned total genetic diversity among regions, among localities within SWIO region, and within localities by performing a hierarchical analysis of molecular variance (AMOVA) using ARLEQUIN 3.1 (Excoffier et al. 2005).

We used the Bayesian clustering method implemented in STRUCTURE 2.0 (Pritchard et al. 2000) that infers the number of populations and assigns individuals to populations. The uppermost hierarchical level of structure within the entire data was detected with the $\Delta K$ statistic (Evanno et al. 2005). In order to estimate each individual's probability of belonging to each population, the non-admixture model with the correlated allele frequencies between populations option was used, and the other parameters were set to their default values. In all cases, STRUCTURE was run using a burn-in period of $10^{5}$ followed by $10^{6}$ Markovchain Monte Carlo (MCMC) sweeps. $F_{\mathrm{ST}}$ estimates, parameters likelihood and ln P(D) (probability of data) were checked to converge before the end of the $10^{5}$ steps of the burn-in period, and run outputs that showed the highest ln P(D) and the lowest Var[ln P(D)] were selected. Individual assignment probabilities were then used to perform a kernel probability density estimation for each population. Kernel density estimates and statistical tests were achieved using R software (R Development Core Team 2007).

IMa analysis. To separately estimate the effects of time and gene flow on the level of genetic divergence, we used the IMa program based on the method described by Hey \& Nielsen (2007) that fits a population divergence model to genetic data (Nielsen \& Wakeley 2001). The isolation-with-migration (IM) model assumes that 2 populations of effective size parameters $q 1$ and $q 2$ diverged from an ancestral population (of effective size parameter $q a$ ) at time $t$, and then exchanged migrants at rates $m 1$ and $m 2$. The coalescent-based approach implemented in IMa provides estimates of the joint posterior probability distribution of these scaled model parameters. Additionally, the timing of simulated migrations events in each genealogy sampled by the MCMC at stationarity can be recorded to generate a posterior distribution of migration times. Partial 16S rRNA sequences of $241 \mathrm{bp}$ were used, 32 from Sumatra individuals, and 28 from Madagascar and Reunion Island samples (haplotypes deposited in GenBank under accession numbers AB278855AB278867). To estimate demographic parameters, 16S rRNA mutation rates ranging from $0.1 \%$ (Lopez et al. 2000) to $0.7 \%$ million $\mathrm{yr}^{-1}$ (Miya \& Nishida 1996) and a 0.25 inheritance scalar were set. We used uniform prior distributions. After preliminary runs to determine the upper bounds of prior distributions, these were set to 20 for $q 1, q 2$ and $q a$, and to 10 for $m 1$, $\mathrm{m} 2$ and $t$. We performed metropolis coupling of Markov chains with a linear heating scheme using 10 chains and a heating term of 0.05 . Each analysis began with a burn-in period of $2 \times 10^{5}$ steps after which $10^{5}$ genealogies were saved every 100 steps for parameter estimation. We expected that $m 1=m 2=0$ under the inherited ancestral polymorphism hypothesis, but $m 1 \neq$ 0 and/or $m 2 \neq 0$ under the alternative hypotheses. These were evaluated by analyzing the distribution of the migration events' mean time, expected to be narrow and close to $t=0$ in the case of recent secondary contact but broad for divergence with gene flow (Nosil 2008).

Data sets simulation. In order to evaluate the power of the statistical methods applied in this study and compare our real data with known models, we built simulated data sets. Microsatellite genotype data of 
2 populations showing a divergence level characterized by $F_{\mathrm{ST}}=0.03$ were simulated using EASYPOP 2.0.1 software (Balloux 2001). Initial genetic diversity was set to 1 allele at each of the 10 loci evolving under a single-step mutation model with a $2 \times 10^{-4}$ mutation rate. To reach the desired divergence level, 5000 males and 5000 females evenly distributed into 2 populations were allowed to computationally evolve in panmixia for $10^{4}$ generations with a migration rate of $5 \times 10^{-4}$ under the island-migration model. 250 individuals were randomly sampled from each population after genotype simulation to represent the parental populations' samples Pop1 and Pop2. These samples were characterized by an average number of 7 (from 5 to 8 ) alleles over the 10 loci and an average observed heterozygosity of 0.70 for Pop 1 and 0.65 for Pop2. We simulated $10^{4} \mathrm{~F}_{1}$ hybrid genotypes (obtained by crossing the 2 parental samples) using HYBRIDLAB 1.0 (Nielsen et al. 2006), and randomly sampled $100 \mathrm{~F}_{1}$ hybrids from among them to build the Hybrid $F_{1}\left(\mathrm{HF}_{1}\right)$ sample.

\section{RESULTS}

\section{Mitochondrial SNP differentiation}

Fig. 1 shows the SNP frequencies at positions 432 and 562 of the 16S rRNA gene from the 5 localities. A highly significant difference of haplotype frequency was observed between Sumatra and the SWIO samples ( $p=$ $\left.4.5 \times 10^{-11}\right)$. While the GC type was dominant in Sumatra $(96 \%)$, it was found at lower frequencies in all SWIO localities (Mayotte 31\%, Madagascar 43\%, Mauritius $31 \%$ and Reunion $27 \%$ ), in which AT was the dominant type. Sumatra showed 3 different haplotypes: GC, AC $(\mathrm{n}=1)$ and AT $(\mathrm{n}=1)$, whereas 2 haplotypes (AT and GC) were observed in SWIO. No significant haplotype frequency difference could be detected among pairs of SWIO localities, or between temporal samples available in Mayotte and Reunion Islands.

The linkage between 16S rRNA SNPs types and control region groups defined by Ishikawa et al. (2004) was tested (sequences from Minegishi et al. 2008). The test revealed that all the AT individuals from the SWIO belonged to the very robust Malagasy group (Group B in Ishikawa et al. 2004) obtained with control region sequences. In contrast, all the GC individuals were nested in the Sumatran branches of the control region tree (Group F in Ishikawa et al. 2004). Thus, the linkage between 16S rRNA and control region markers allowed us to identify the D-loop group simply by genotyping two 16S rRNA SNPs. Interestingly, the 2 AT and AC specimens found in Sumatra presented the same Indonesian control region type as the GC individuals (Group F).

\section{Nuclear genetic diversity, HWE and linkage disequilibrium}

Population and locus-specific genetic diversity indices are provided in the Appendix, Table A1. All samples showed similar levels of polymorphism, with observed heterozygosities ranging from 0.484 (Sumatra) to 0.513 (Reunion), and expected heterozygosities ranging from 0.492 (Sumatra) to 0.536 (Reunion). Allelic richness (AR) $( \pm \mathrm{SE})$ was also similar in all samples (Mayotte: $\mathrm{AR}=$ $7.40 \pm 4.27$; Madagascar: $\mathrm{AR}=6.80 \pm 3.68$; Reunion: $\mathrm{AR}=7.70 \pm 4.50$; Mauritius: $\mathrm{AR}=7.9 \pm 4.43$; Sumatra: $\mathrm{AR}=6.60 \pm 3.98$ ). Comparisons of $H_{\mathrm{o}}, H_{\mathrm{e}}$ and AR across samples using 1-way ANOVA were statistically not significant $\left(H_{\mathrm{o}}: \mathrm{p}=0.999 ; H_{\mathrm{e}}: \mathrm{p}=0.997\right.$; AR: $\left.\mathrm{p}=0.947\right)$. Significant departures from HWE corresponding to heterozygote deficiencies were observed in Mauritius $(\mathrm{p}=0.0275)$ and Reunion $(\mathrm{p}<0.001)$. A significant within-sample genetic linkage was found for 7 pairs of loci among the 225 tested, but given that disequilibria involved different pairs of loci from one sample to another, these loci were unlikely to be physically linked.

\section{Nuclear genetic differentiation among samples}

We evaluated the separate effects of temporal and spatial genetic variation independently with the temporal samples available in the SWIO. Genetic variation among annual cohorts of a locality was tested in Reunion and Mayotte between 2005 and 2006, although some temporal sample sizes were low in this particular analysis (MayM6: $\mathrm{N}=15$; ReuAM5: $\mathrm{N}=21$, see Table 1 for sample abbreviations). No significant genetic variation was detected between temporal samples in Mayotte $\left(F_{\mathrm{ST}}=0.002, \mathrm{~ns}\right)$ and Reunion Islands $\left(F_{\mathrm{ST}}=0.010\right.$, ns). Spatial genetic variation among synchronous samples consisting of glass eels and elvers of different geographical locations was not significant in 2006 (global $F_{\mathrm{ST}}=0.005, \mathrm{~ns}$ ) but significant in 2007 (global $F_{\mathrm{ST}}=$ $0.005, \mathrm{p}=0.037$ ). However, geographic differentiation between SWIO synchronous cohorts was not supported by the 9 possible pairwise comparisons, all of which gave non significant $F_{\mathrm{ST}}$ values.

Temporal homogeneity among the annual cohorts in SWIO justified the grouping of samples from each locality for the study of Anguilla marmorata genetic structure in the Indian Ocean. A weak but highly significant genetic differentiation was detected among these 5 samples (global $F_{\mathrm{ST}}=0.009, \mathrm{p}<0.0001$ ). Although most of the genetic variation was found within localities (96.96\%), the proportion of total genetic variation evidenced among Sumatra and SWIO regions $(2.77 \%)$ was 10 times higher than that found among localities within the SWIO $(0.27 \%)$ (AMOVA). This result was supported by the 
highly significant pairwise $F_{\mathrm{ST}}$ values, ranging from 0.025 to 0.039 ( $\mathrm{p}<0.0001$ ) obtained between Sumatra and SWIO localities (Table 3 ). These $F_{\mathrm{ST}}$ values were negatively correlated with the GC SNP proportions found in the corresponding SWIO localities (Spearman's $\left.\mathrm{r}_{\mathrm{S}}=-0.949, \mathrm{p}=0.026\right)$. The east-west genetic differentiation was also supported by highly significant Fisher's exact tests of allelic frequencies heterogeneity among samples ( $\mathrm{p}<0.0001)$. Among the 10 microsatellite markers analyzed, 8 loci showed significant frequency variation in pairwise comparisons between Sumatra and SWIO localities. A small but significant genetic differentiation was found between Mayotte and Reunion Islands $\left(F_{\mathrm{ST}}=0.006, \mathrm{p}=0.017\right)$, suggesting a more subtle genetic structure within the SWIO region. However, no significant pairwise $F_{\mathrm{ST}}$ value or overall allelic frequencies difference was found among Mauritius, Madagascar and Mayotte samples.

\section{Estimation of demographic parameters using the IM model}

The marginal posterior probability curves for migration rate parameters showed $m 1=0$ and $m 2 \neq 0$ (Fig. 2).

Table 3. Anguilla marmorata. Pairwise $F_{\mathrm{ST}}$ values calculated between localities (whole samples) based on 10 microsatellite loci. Significant values after Bonferroni correction are shown in bold. For abbreviations see Table $1 .{ }^{*} \mathrm{p}<0.05,{ }^{* *} \mathrm{p}<0.01$ and ${ }^{* * *} \mathrm{p}<0.0001$

\begin{tabular}{|lcrcc|}
\hline Samples & Mad & Mau & Reu & Sum \\
\hline May & \multirow{2}{*}{0.001} & 0.0005 & $\mathbf{0 . 0 0 6 2}^{* *}$ & $\mathbf{0 . 0 2 9 7}^{* * *}$ \\
Mad & & -0.0012 & $0.0046^{*}$ & $\mathbf{0 . 0 2 4 7}^{\text {****}}$ \\
Mau & & & $0.0043^{*}$ & $\mathbf{0 . 0 2 8 3}^{* * *}$ \\
Reu & & & & $\mathbf{0 . 0 3 8 8}^{\text {*** }}$ \\
\hline
\end{tabular}

This supports the hypothesis of unidirectional migration from Sumatra to the SWIO and undermines the ancestral polymorphism hypothesis. The probability distribution of the mean time of migration events was narrow and close to 0 , suggesting that a recent secondary contact after a period of isolation was more likely than ongoing gene flow during the divergence process (Fig. 2). Probability density estimates of scaled parameters $q 1$ and $q 2$, proportional to the effective population sizes, revealed that the SWIO population could have an effective population size 10 times higher than the Sumatra one. Using 2 extreme molecular clocks of $0.1 \%$ per million years (Myr) (Lopez et al. 2000) and $0.7 \% \mathrm{Myr}^{-1}$ (Miya \& Nishida 1996), the time of population split was estimated to range from 100000 to $700000 \mathrm{yr}$.

\section{Bayesian individual assignments with microsatellite data}

The $\Delta K$ statistic (Evanno et al. 2005) succeeded in detecting the right number of clusters when the 2 simulated parental populations showing a low divergence level $\left(F_{\mathrm{ST}}=0.03\right)$ were analyzed together with the Bayesian assignment method implemented in STRUCTURE (Pritchard et al. 2000). Thus, the $\Delta K$ seemed powerful enough to correctly detect 2 low diverging populations with 10 microsatellite markers. When applied to the real microsatellite data, the $\Delta K$ method indicated the existence of 2 populations in the Indian Ocean. Assignment probabilities were then computed using the non-admixture model with $K=2$, because the admixture model failed to perform well due to the low level of genetic divergence in the data. The Wilcoxon-Mann-Whitney test showed non-identical rank distribution between individual assignment probability values of mitochondrial AT and GC groups in
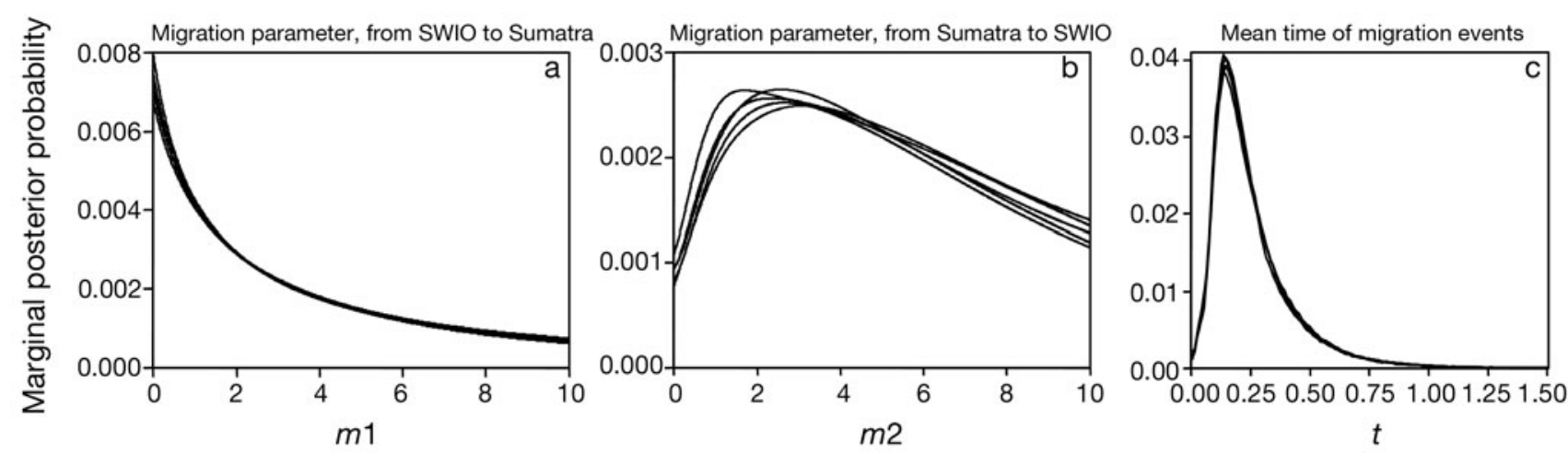

Fig. 2. Anguilla marmorata. Marginal posterior probability distributions for migration rates parameters (a) $m 1$ and (b) $m 2$, and (c) mean time $(t)$ of migration events from population divergence to the present day (all parameters are scaled by the mutation rate). Calculations were based on partial 16S rRNA sequences. The 5 curves in each plot correspond to probability distributions obtained over 5 runs, using identical prior distributions and parameter settings but different seed numbers. A linear heating scheme was used for multiple Markov-coupled chains running with 10 chains and a heating term of 0.05, swapping rates between successive chains ranged between 19 and $72 \%$. SWIO: Southwest Indian Ocean 
the SWIO, with higher ranks being found in the AT than in the GC group ( $p=0.005$ ). Thus, a cytonuclear disequilibrium was evidenced in the SWIO between the nuclear genotypes of individuals showing SWIO mitochondrial haplotypes and those belonging to the Sumatran mitochondrial group. Fig. 3 illustrates the contrasted probability density patterns found between the AT and GC mitochondrial groups in each SWIO locality, in comparison with the probability density of Sumatra.

Individual assignment probabilities were estimated under the same conditions on a simulated data set built by joining the Pop1, Pop2 and $\mathrm{HF}_{1}$ simulated samples. Models were then constructed by randomly sampling

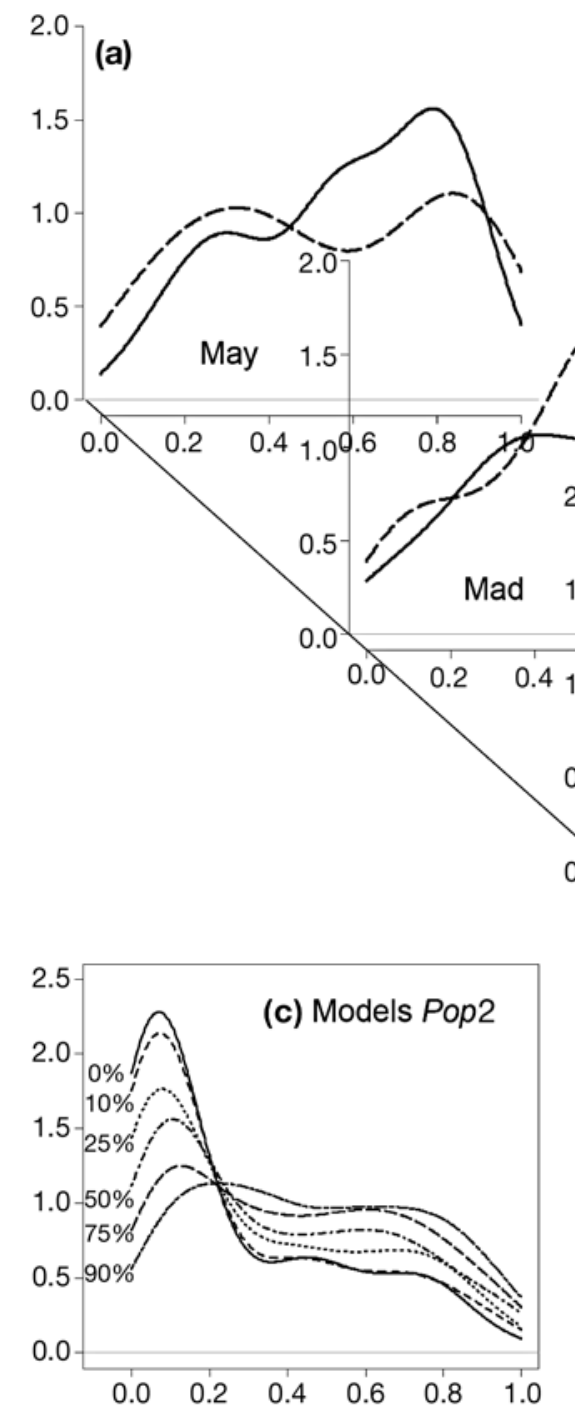

assignment probabilities of hybrids and purebreds from the same population, so that the hybrid proportion in models ranged from 0 (only purebreds) to $90 \%$. Fig. 3b,c shows the probability densities estimated for 6 population models built with each parental population. Contrasted patterns of assignment probability density between the models in Fig. $3 \mathrm{~b}$ and those in Fig. 3c showed that density patterns could be distinguished even though low genetic divergence weakens individual assignment probability estimation. Empirical probability distributions of each locality were then compared to the 12 probability distributions obtained with simulated populations using a KolmogorovSmirnov test (Table 4).

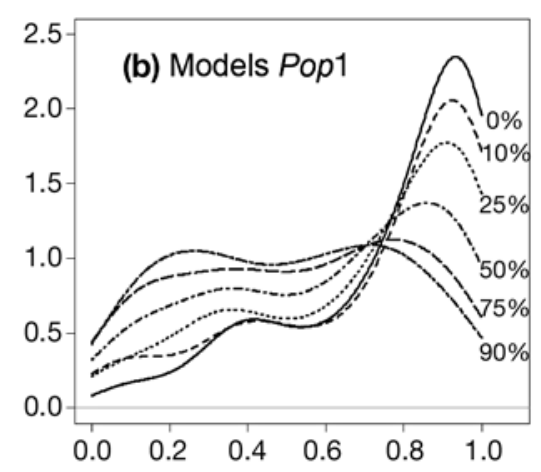

Fig. 3. Anguilla marmorata. (a) Probability density estimates (drawn from individual assignment probabilities estimated for 2 clusters with STRUCTURE) for Mayotte (May), Madagascar (Mad), Reunion (Reu), Mauritius (Mau) and Sumatra (Sum). Southwest Indian Ocean (SWIO) haplotype groups' densities were estimated separately and represented as full lines for the AT group and dotted lines for the GC group. Individual probability of belonging to the SWIO population increases from 0 to 1 on the abscissa axes, and is inversely proportional to the probability of belonging to the Sumatra population. Probability densities estimated for simulated populations: (b) Pop1 and (c) Pop2 with $\mathrm{F}_{1}$ hybrid proportions varying from 0 to $90 \%$ 
Table 4. Anguilla marmorata. Kolmogorov-Smirnov test for similarity between empirical probability distributions estimated for haplotype groups of each locality and probability distribution of the 12 theoretical models. Only the fitted models for which empirical distribution did not show significant difference at the $5 \%$ level are presented. For each haplotype group of each locality, the fitted model showing the lowest Kolmogorov-Smirnov statistic was considered as the best fitted model. Percentages refer to the proportion of hybrids in the fitted models

\begin{tabular}{|lcccc|}
\hline Locality & $\begin{array}{c}\text { Haplotype } \\
\text { group }\end{array}$ & $\begin{array}{c}\text { Fitted } \\
\text { models } \\
\text { Pop1 }(\%)\end{array}$ & $\begin{array}{c}\text { Fitted } \\
\text { models } \\
\text { Pop2 }(\%)\end{array}$ & $\begin{array}{c}\text { Best } \\
\text { model } \\
(\%)\end{array}$ \\
\hline Mayotte & AT & $50-90$ & No fit & Pop1-75 \\
& GC & $25-90$ & $75-90$ & Pop1-75 \\
Madagascar & AT & $50-90$ & 90 & Pop1-75 \\
& GC & $75-90$ & $75-90$ & Pop1-90 \\
Reunion & AT & $50-90$ & $75-90$ & Pop1-90 \\
Mauritius & GC & $50-90$ & $25-90$ & Pop2-75 \\
Sumatra & GC & $50-90$ & 90 & Pop1-75 \\
& & No fit & $25-90$ & Pop2-75 \\
Gop2-0
\end{tabular}

\section{DISCUSSION}

\section{Confirmation of 2 populations in the Indian Ocean}

The genetic differentiation found at microsatellite loci and mitochondrial SNPs between Sumatra and SWIO localities suggested nonrandom mating among eels from the eastern and western sides of the Indian Ocean. Moreover, the $\Delta K$ statistic (Evanno et al. 2005) revealed the existence of 2 distinct genetic groups based on microsatellite variation. Therefore, this study confirms the existence of 2 populations of Anguilla marmorata in the Indian Ocean.

The results of mitochondrial SNP variations obtained here confirmed previous findings, since east-west mitochondrial differentiation was already observed by Ishikawa et al. (2004) and Minegishi et al. (2008). Both detected a cluster of SWIO haplotypes supported by a $100 \%$ bootstrap (Group B in Ishikawa et al. 2004), contrasting with a less robust group of haplotypes in which all Sumatra individuals clustered with some from SWIO (Group F). The perfect linkage between the 16S rRNA gene and the control region on the mitochondrial chromosome enabled a comparison with earlier findings, given that the SWIO AT association corresponded to the control region Group B, whereas individuals from Group F had the GC combination (except for 2 specimens from Sumatra that had AT and AC association). Our results were then consistent with previous studies, since $100 \%$ of Sumatra samples displayed Sumatran haplotypes, whereas SWIO eels were characterized by a mixture of SWIO and Sumatran haplotypes. In addition, the mean proportion of Indonesian haplotypes found in SWIO localities lay between those independently observed in the 2 former surveys (43\% in Ishikawa et al. 2004, $20 \%$ in Minegishi et al. 2008, 33\% in the present study). However, the significant genetic differentiation between Sumatra and SWIO observed in our study using 10 microsatellite loci contrasts with the lack of differentiation found by Minegishi et al. (2008) using 8 microsatellite loci. This might be due to Minegishi et al.'s (2008) sample size's (Reunion: $\mathrm{N}=34$; Madagascar: $\mathrm{N}=33$ ) limiting the observation of rare genotypes in SWIO. Despite their lack of statistical testing, the results from Ishikawa et al. (2004) seemed to better match the present study, as the $12 \%$ average of AFLP band difference found between Sumatra and Madagascar exceeded the within locality averages of 6.9 and $8 \%$, respectively.

There is currently no ecological evidence supporting the existence of 2 breeding sites of Anguilla marmorata in the Indian Ocean. Larvae of this species could only be identified northeast of Madagascar during the Dana expedition (Jespersen 1942), although some unidentified small leptocephali captured southwest of Sumatra were possibly coming from a putative Sumatran spawning area of $A$. marmorata. Spatial separation of spawning is, however, not necessary to explain genetic differentiation, as significant pairwise $F_{\mathrm{ST}}$ values ranging between 0.007 and 0.040 were found between the 2 Atlantic species A. anguilla and A. rostrata (Wirth \& Bernatchez 2003), whose spawning areas nevertheless partially overlap in the Sargasso Sea. In this case, the significant pairwise $F_{\mathrm{ST}}$ values calculated here among Sumatra and SWIO localities $\left(F_{\mathrm{ST}}=0.025\right.$ to 0.039$)$ could alternatively be the consequence of temporal delay between the reproduction of adult eels from different locations. Therefore we hypothesize the existence of 2 geographically and/or temporally separated spawning areas between SWIO and Sumatra populations.

\section{Evidence of current unidirectional gene flow}

The haplotype diversity found in SWIO can be explained either by polymorphism inherited from the ancestral population, ongoing gene flow during divergence, or secondary contact between Sumatra and SWIO populations after isolation. IMa simulations based on partial 16S rRNA sequences suggested a period of isolation followed by modern unidirectional migration from Sumatra to SWIO as the most likely scenario.

The recent mean time of migration events estimated from mitochondrial data was supported by the analysis 
of microsatellite data. Although nuclear data could not allow the assignment of individuals to their population with a high probability, AT individuals showed higher ranks of assignment probabilities to the SWIO population than GC specimens, indicating the existence of a cytonuclear disequilibrium in the SWIO. This result was strengthened by the significant negative correlation found between GC proportions in SWIO localities and the microsatellite pairwise $F_{\mathrm{ST}}$ values calculated between Sumatra and SWIO localities, which indicate that SWIO GC individuals are more closely related to Indonesian eels than SWIO AT specimens. This disequilibrium observed between the nuclear genotypes of AT and GC groups in the SWIO suggests that the secondary contact evidenced by mitochondrial data analysis is still in progress. Indeed, if Sumatra migrants do not contribute to the SWIO breeding pool, disequilibrium should disappear at the end of the migrants' lives if migration is not maintained. Alternatively, if Sumatra migrants interbreed with the local SWIO population, cytonuclear disequilibrium should be divided by 2 at each generation and would rapidly be undetectable after the end of the secondary contact. Therefore, a current inflow of Sumatra migrants to the SWIO region is necessary to explain the observed cytonuclear disequilibrium. This contemporary migration could also account for the significant heterozygote deficiencies evidenced in Reunion and Mauritius.

The next step aimed at testing whether Indonesian migrants were possibly mating with individuals from the SWIO population. The Sumatra population assignment probability distribution, which had best fitted the model containing only Pop2 individuals, indicated that the Sumatra sample came from a rather homogeneous population. By contrast, the probability distributions of SWIO GC and AT groups did not fit the simulated Pop2 and Pop1 distributions, respectively, as would be expected if GC individuals were first-generation migrants from the Sumatra population and if AT individuals composed the SWIO population. Tests for goodness-of-fit with the different models assuming co-occurrence of purebreds and $F_{1}$ hybrids indicated that genetic admixture could better account for the SWIO groups' composition. The best fitted models for SWIO GC groups moreover suggested that Sumatra migrants preferentially reached the easternmost SWIO localities, which explained why significant heterozygote deficiencies were observed in Reunion and Mauritius, whereas Mayotte and Madagascar samples did not depart from HWE heterozygote proportions. Therefore, we propose that the secondary contact between Sumatra and SWIO populations is accompanied by interbreeding between SWIO individuals and Indonesian migrants, resulting in the high proportions of hybrids in the models fitted for SWIO groups. In order to simplify the tests, we used models assuming purebreds and $\mathrm{F}_{1}$ hybrids only. However, later-generation hybrids could also occur in reality, since it was shown that the Atlantic eel species produce hybrids beyond the first generation in Iceland (Albert et al. 2006). For this reason, the eventuality for introgressive hybridization in SWIO could not be rejected.

Several elements must be integrated to provide a new interpretation of Anguilla marmorata's evolutionary history in the Indian Ocean. The estimation of the time of divergence between Sumatra and SWIO populations, although it should be taken with care, showed that the split could have occurred from 100000 to 700000 yr ago. This corresponds to the Pleistocene period, when important climatic oscillations induced significant sea level variations. The 120 to $150 \mathrm{~m}$ sea level decrease (from the present level) during glacial maxima (Voris 2000) probably provoked changes in the Indian Ocean current configuration, which modified larval dispersal. Allopatric differentiation between eastern and western Indian Ocean populations could also have occurred as a consequence of the Mascarene ridge emergence, which was provoked by marine regression. Then, after a period of isolation without gene flow, a secondary contact, possibly initiated by new environmental changes, led to the current population structure. As illustrated in Fig. 1, SWIO localities are presently under the influence of the South Equatorial Current flowing from east to west. Since the secondary contact is also orientated westward, its direction is probably linked to larval dispersal. In such a case, Mauritius and Reunion islands could more likely receive leptocephali larvae dispersed by the South Equatorial Current from a Sumatran spawning area than Madagascar and Mayotte, explaining why migrants were preferentially found in the easternmost locations of SWIO. This could also explain why larval duration variance was found to be twice as high in Mauritius as in Mayotte and Madagascar (Réveillac et al. 2008, Robinet et al. 2008).

We hypothesize that larval dispersal driven by the South Equatorial Current could presently induce some leptocephali transport from an unknown Sumatran spawning area to SWIO localities. Because Indonesian migrants seem to integrate into the SWIO breeding pool, the consequent new allelic combinations arising in the SWIO population can represent an adaptive potential to natural selection, if admixture is accompanied by genetic introgression in SWIO (Seehausen 2004). Hence, future studies will need to identify the potential variety of pedigrees generated by genetic admixture at the individual level and specifically address the adaptive aspects of the secondary contact evinced in SWIO. 
Acknowledgements. The authors are grateful to the following people involved in sampling procedures: M. W. Rabenevanana and G. Lasserre from the Institut Halieutique des Sciences Marines (University of Tulear, Madagascar), P. Valade, H. P. Grondin and V. Bouju from the Association Réunionnaise de Développement de l'Aquaculture (Reunion Island), P. Sasal from the University of Perpignan, and R. LecomteFiniger from the Ecole Pratique des Hautes Etudes of Perpignan. We also thank N. Bierne from the University of Montpellier II, the contributing MEPS editor, and 4 anonymous referees for their constructive comments. This work was supported by grants from EU INTERREG3B 'Anguilles du Sud Ouest de l'Océan Indien.'

\section{LITERATURE CITED}

Albert V, Jonsson B, Bernatchez L (2006) Natural hybrids in Atlantic eels (Anguilla anguilla, A. rostrata): evidence for successful reproduction and fluctuating abundance in space and time. Mol Ecol 15:1903-1916

Balloux F (2001) EASYPOP (version 1.7): a computer program for population genetics simulations. J Hered 92:301-302

Belkhir K, Borsa P, Chikhi L, Raufaste N, Bonhomme F (2004) GENETIX 4.05: logiciel sous Windows pour la génétique des populations. Laboratoire Génome, Populations, Interactions, CNRS UMR 5171, Université de Montpellier II, Montpellier

Comparini A, Rizzotti M, Rodino E (1977) Genetic control and variability of phosphoglucose isomerase (PGI) in eels from the Atlantic Ocean and the Mediterranean Sea. Mar Biol 43:109-116

> Daemen E, Cross T, Ollevier F, Volckaert FAM (2001) Analysis of the genetic structure of European eel (Anguilla anguilla) using microsatellite DNA and mtDNA markers. Mar Biol 139:755-764

Dannewitz J, Maes GE, Johansson L, Wickström H, Volckaert FAM, Järvi T (2005) Panmixia in the European eel: a matter of time ... Proc R Soc Lond B Biol Sci 272:1129-1137

> De Ligny W, Pantelouris EM (1973) Origin of the European eel. Nature 246:518-519

> Evanno G, Regnaut S, Goudet J (2005) Detecting the number of clusters of individuals using the software STRUCTURE: a simulation study. Mol Ecol 14:2611-2620

Excoffier L, Laval G, Schneider S (2005) Arlequin ver. 3.0: an integrated software package for population genetics data analysis. Evol Bioinform Online 1:47-50

Gagnaire PA, Tsukamoto K, Aoyama J, Minegishi Y, Valade P, Berrebi P (2007) RFLP and semi-multiplex PCR-based identification of four eel species from the south-western Indian Ocean region. J Fish Biol 71(Sup B):279-287

Hey J, Nielsen R (2007) Integration within the Felsenstein equation for improved Markov chain Monte Carlo methods in population genetics. Proc Natl Acad Sci USA 104: 2785-2790

Ishikawa S, Tsukamoto K, Nishida M (2001) Characterization of microsatellite loci from the Japanese eel Anguilla japonica. Mol Ecol Notes 1:140-142

Ishikawa S, Tsukamoto K, Nishida M (2004) Genetic evidence for multiple geographic populations of the giant mottled eel Anguilla marmorata in the Pacific and Indian Oceans. Ichthyol Res 51:343-353

Jespersen P (1942) Indo-Pacific leptocephalids of the genus Anguilla: systematic and biological studies. Dana-Rep Carlsberg Found 22:1-128

Lintas C, Hirano J, Archer S (1998) Genetic variation of the European eel (Anguilla anguilla). Mol Mar Biol Biotechnol 7:263-269
Lopez JA, Bentzen P, Pietsch TW (2000) Phylogenetic relationships of Esocoid fishes (Teleostei) based on partial cytochrome $b$ and $16 \mathrm{~S}$ mitochondrial DNA sequences. Copeia 2:420-431

> Maes GE, Volckaert FAM (2002) Clinal genetic variation and isolation by distance in the European eel Anguilla anguilla (L.). Biol J Linn Soc 77:509-521

McCleave JD, Brickley PJ, O'Brien KM, Kistner DA, Wong MW, Gallagher M, Watson SM (1998) Do leptocephali of the European eel swim to reach continental waters? Status of the question. J Mar Biol Assoc UK 78:285-306

Miller MJ, Mochioka N, Otake T, Tsukamoto K (2002) Evidence of a spawning area of Anguilla marmorata in the western North Pacific. Mar Biol 140:809-814

Minegishi Y, Aoyama J, Tsukamoto K (2008) Multiple population structure of the giant mottled eel Anguilla marmorata. Mol Ecol 17:3109-3122

> Miya M, Nishida M (1996) Molecular phylogenetic perspective on the evolution of the deep-sea fish genus Cyclothone (Stomiiformes: Gonostomatidae). Ichthyol Res 43:375-398

Nielsen R, Wakeley J (2001) Distinguishing migration from isolation: a Markov chain Monte Carlo approach. Genetics 158:885-896

Nielsen EEG, Bach LA, Kotlicki P (2006) HYBRIDLAB (version 1.0): a program for generating simulated hybrids from population samples. Mol Ecol Notes 6:971-973

> Nosil P (2008) Speciation with gene flow could be common. Mol Ecol 17:2103-2106

> Pritchard JK, Stephens M, Donnelly P (2000) Inference of population structure using multilocus genetic data. Genetics 155:945-959

> Pujolar JM, Maes GE, Volckaert FAM (2006) Genetic patchiness among recruits in the European eel Anguilla anguilla. Mar Ecol Prog Ser 307:209-217

R Development Core Team (2007) R: a language and environment for statistical computing. R Foundation for Statistical Computing, Vienna. www.R-project.org

Raymond M, Rousset F (1995) GENEPOP (version 1.2): population genetics software for exact tests and ecumenicism. J Hered 86:248-249

Réveillac E, Feunteun E, Berrebi P, Gagnaire PA, LecomteFiniger R, Bosc P, Robinet T (2008) Anguilla marmorata larval migration plasticity as revealed by otolith microstructural analysis. Can J Fish Aquat Sci 65:2127-2137

Robinet T, Guyet S, Marquet G, Mounaix B and others (2003) Elver invasion, population structure and growth of marbled eels Anguilla marmorata in a tropical river on Reunion Island in the Indian Ocean. Environ Biol Fishes 68:339-348

Robinet T, Réveillac E, Kuroki M, Aoyama J and others (2008) New clues for freshwater eels (Anguilla spp.) migration routes to eastern Madagascar and surrounding islands. Mar Biol 154:453-463

Sambrook J, Fritsch EF, Maniatis T (1989) Molecular cloning: a laboratory manual, 2nd edn. Cold Spring Harbor Laboratory Press, New York

> Sang TK, Chang HY, Chen CT, Hui CF (1994) Population structure of the Japanese eel, Anguilla japonica. Mol Biol Evol 11:250-260

Schmidt J The breeding places of the eel (1925) Smithson Inst Annu Rep 1924:279-316

Schott FA, McCreary JP Jr (2001) The monsoon circulation of the Indian Ocean. Prog Oceanogr 51:1-123

> Seehausen O (2004) Hybridization and adaptative radiation. Trends Ecol Evol 19:198-207

> Tseng MC, Chen CA, Kao HW, Tzeng WN, Lee SC (2001) Polymorphisms of GA/GT microsatellite loci from Anguilla 
japonica. Mar Biotechnol 3:275-280

Tsukamoto K, Aoyama J, Miller MJ (2002) Migration, speciation, and the evolution of diadromy in anguillid eels. Can J Fish Aquat Sci 59:1989-1998

Voris HK (2000) Maps of Pleistocene sea levels in South East Asia: shorelines, river systems, time durations. J Biogeogr 27:1153-1167

Waples RS (1998) Separating the wheat from the chaff: Patterns of genetic differentiation in high gene flow species. J Hered 89:438-450
Ward RD, Woodwark M, Skibinski DOF (1994) A comparison of genetic diversity levels in marine, freshwater, and anadromous fishes. J Fish Biol 44:213-232

- Weir BS, Cockerham CC (1984) Estimating F-statistics for the analysis of population structure. Evolution 38: 1358-1370

Wirth T, Bernatchez L (2001) Genetic evidence against panmixia in the European eel. Nature 409:1037-1040

Wirth T, Bernatchez L (2003) Decline of North Atlantic eels: a fatal synergy? Proc R Soc Lond B Biol Sci 270:681-688

Appendix. Table A1. Anguilla marmorata. Population and locus-specific genetic diversity indices. HWE: Hardy-Weinberg equilibrium; ns: not significant. ${ }^{*} \mathrm{p}<0.05,{ }^{* *} \mathrm{p}<0.01$ and ${ }^{* * *} \mathrm{p}<0.001$

\begin{tabular}{|c|c|c|c|c|c|c|}
\hline Locus & & $\begin{array}{l}\text { Mayotte } \\
\mathrm{N}=102\end{array}$ & $\begin{array}{c}\text { Madagascar } \\
\quad \mathrm{N}=88\end{array}$ & $\begin{array}{l}\text { Reunion } \\
\mathrm{N}=102\end{array}$ & $\begin{array}{l}\text { Mauritius } \\
\mathrm{N}=106\end{array}$ & $\begin{array}{l}\text { Sumatra } \\
\mathrm{N}=46\end{array}$ \\
\hline AJMS-3 & $\begin{array}{c}\text { Number of alleles } \\
H_{\mathrm{o}} \\
H_{\mathrm{e}} \\
\text { HWE test }\end{array}$ & $\begin{array}{c}2 \\
0.343 \\
0.346 \\
\mathrm{~ns}\end{array}$ & $\begin{array}{c}2 \\
0.375 \\
0.334 \\
\text { ns }\end{array}$ & $\begin{array}{c}2 \\
0.436 \\
0.455 \\
\text { ns }\end{array}$ & $\begin{array}{c}2 \\
0.377 \\
0.352 \\
\text { ns }\end{array}$ & $\begin{array}{c}3 \\
0.130 \\
0.144 \\
\text { ns }\end{array}$ \\
\hline Aro054 & $\begin{array}{c}\text { Number of alleles } \\
H_{\mathrm{o}} \\
H_{\mathrm{e}} \\
\text { HWE test }\end{array}$ & $\begin{array}{c}5 \\
0.167 \\
0.158 \\
\text { ns }\end{array}$ & $\begin{array}{c}6 \\
0.205 \\
0.200 \\
\text { ns }\end{array}$ & $\begin{array}{c}4 \\
0.167 \\
0.157 \\
\text { ns }\end{array}$ & $\begin{array}{c}5 \\
0.179 \\
0.169 \\
\text { ns }\end{array}$ & $\begin{array}{c}4 \\
0.109 \\
0.106 \\
\text { ns }\end{array}$ \\
\hline AjTR-04 & $\begin{array}{c}\text { Number of alleles } \\
H_{\mathrm{o}} \\
H_{\mathrm{e}} \\
\text { HWE test }\end{array}$ & $\begin{array}{l}12 \\
0.618 \\
0.571 \\
\mathrm{~ns}\end{array}$ & $\begin{array}{c}8 \\
0.409 \\
0.458 \\
\text { ns }\end{array}$ & $\begin{array}{c}9 \\
0.461 \\
0.461 \\
\mathrm{~ns}\end{array}$ & $\begin{array}{c}10 \\
0.519 \\
0.504 \\
\mathrm{~ns}\end{array}$ & $\begin{array}{c}5 \\
0.370 \\
0.456 \\
\text { ns }\end{array}$ \\
\hline AjTR-12 & $\begin{array}{c}\text { Number of alleles } \\
H_{\mathrm{o}} \\
H_{\mathrm{e}} \\
\text { HWE test }\end{array}$ & $\begin{array}{c}3 \\
0.029 \\
0.029 \\
\text { ns }\end{array}$ & $\begin{array}{c}5 \\
0.114 \\
0.152 \\
* * *\end{array}$ & $\begin{array}{c}5 \\
0.098 \\
0.095 \\
\mathrm{~ns}\end{array}$ & $\begin{array}{c}5 \\
0.066 \\
0.083 \\
\mathrm{~ns}\end{array}$ & $\begin{array}{c}4 \\
0.174 \\
0.165 \\
\text { ns }\end{array}$ \\
\hline AjTR-37 & $\begin{array}{c}\text { Number of alleles } \\
H_{\mathrm{o}} \\
H_{\mathrm{e}} \\
\text { HWE test }\end{array}$ & $\begin{array}{c}8 \\
0.667 \\
0.651 \\
\text { ns }\end{array}$ & $\begin{array}{c}7 \\
0.546 \\
0.597 \\
\text { ns }\end{array}$ & $\begin{array}{c}7 \\
0.706 \\
0.677 \\
\mathrm{~ns}\end{array}$ & $\begin{array}{c}8 \\
0.613 \\
0.592 \\
\mathrm{~ns}\end{array}$ & $\begin{array}{c}8 \\
0.739 \\
0.734 \\
\text { ns }\end{array}$ \\
\hline AjTR-45 & $\begin{array}{c}\text { Number of alleles } \\
H_{\mathrm{o}} \\
H_{\mathrm{e}} \\
\text { HWE test }\end{array}$ & $\begin{array}{c}5 \\
0.520 \\
0.540 \\
\mathrm{~ns}\end{array}$ & $\begin{array}{c}4 \\
0.568 \\
0.532 \\
\mathrm{~ns}\end{array}$ & $\begin{array}{c}6 \\
0.578 \\
0.561 \\
\mathrm{~ns}\end{array}$ & $\begin{array}{c}5 \\
0.576 \\
0.507 \\
\mathrm{~ns}\end{array}$ & $\begin{array}{c}3 \\
0.644 \\
0.563 \\
\text { ns }\end{array}$ \\
\hline AJMS-6 & $\begin{array}{c}\text { Number of alleles } \\
H_{\mathrm{o}} \\
H_{\mathrm{e}} \\
\text { HWE test }\end{array}$ & $\begin{array}{c}6 \\
0.735 \\
0.626 \\
\text { ns }\end{array}$ & $\begin{array}{c}5 \\
0.705 \\
0.671 \\
\text { ns }\end{array}$ & $\begin{array}{c}5 \\
0.677 \\
0.640 \\
\text { ns }\end{array}$ & $\begin{array}{c}6 \\
0.576 \\
0.669 \\
\text { ns }\end{array}$ & $\begin{array}{c}7 \\
0.696 \\
0.668 \\
\text { ns }\end{array}$ \\
\hline AJMS-10 & $\begin{array}{c}\text { Number of alleles } \\
H_{\mathrm{o}} \\
H_{\mathrm{e}} \\
\text { HWE test }\end{array}$ & $\begin{array}{c}7 \\
0.382 \\
0.501 \\
* * *\end{array}$ & $\begin{array}{c}5 \\
0.523 \\
0.524 \\
\mathrm{~ns}\end{array}$ & $\begin{array}{c}9 \\
0.485 \\
0.655 \\
* * *\end{array}$ & $\begin{array}{c}8 \\
0.491 \\
0.628 \\
* *\end{array}$ & $\begin{array}{c}5 \\
0.326 \\
0.424 \\
*\end{array}$ \\
\hline Aro063 & $\begin{array}{c}\text { Number of alleles } \\
H_{\mathrm{o}} \\
H_{\mathrm{e}} \\
\text { HWE test }\end{array}$ & $\begin{array}{l}16 \\
0.640 \\
0.757 \\
* *\end{array}$ & $\begin{array}{c}14 \\
0.674 \\
0.790 \\
{ }_{*}^{*}\end{array}$ & $\begin{array}{l}17 \\
0.667 \\
0.779 \\
* *\end{array}$ & $\begin{array}{l}17 \\
0.708 \\
0.765 \\
\text { ns }\end{array}$ & $\begin{array}{c}14 \\
0.848 \\
0.840 \\
\text { ns }\end{array}$ \\
\hline Aro095 & $\begin{array}{c}\text { Number of alleles } \\
H_{\mathrm{o}} \\
H_{\mathrm{e}} \\
\text { HWE test }\end{array}$ & $\begin{array}{c}10 \\
0.843 \\
0.855 \\
\mathrm{~ns}\end{array}$ & $\begin{array}{l}12 \\
0.852 \\
0.870 \\
\text { ns }\end{array}$ & $\begin{array}{l}13 \\
0.852 \\
0.865 \\
\text { ns }\end{array}$ & $\begin{array}{c}13 \\
0.859 \\
0.873 \\
\text { ns }\end{array}$ & $\begin{array}{l}13 \\
0.804 \\
0.817 \\
\text { ns }\end{array}$ \\
\hline Over all loci & $\begin{array}{c}\text { Mean number of alleles } \\
H_{\mathrm{o}} \\
H_{\mathrm{e}} \\
\text { HWE test }\end{array}$ & $\begin{array}{l}7.4 \\
0.494 \\
0.503 \\
\text { ns }\end{array}$ & $\begin{array}{l}6.8 \\
0.497 \\
0.513 \\
\text { ns }\end{array}$ & $\begin{array}{l}7.7 \\
0.513 \\
0.536 \\
* * *\end{array}$ & $\begin{array}{c}7.9 \\
0.496 \\
0.514 \\
*\end{array}$ & $\begin{array}{l}6.6 \\
0.484 \\
0.492 \\
\text { ns }\end{array}$ \\
\hline
\end{tabular}

